\title{
Some production outcomes when management practices and deer behaviour interact
}

\author{
J.C. POLLARD and D.R. STEVENS \\ AgResearch, Invermay Agricultural Centre, Private Bag 50034, Mosgiel, New Zealand \\ jo.pollard@agresearch.co.nz
}

\begin{abstract}
There are three key times during the year when deer management interacts with behavioural needs to influence productivity. At calving time, average neonatal losses are $10-12 \%$. The most common causes of perinatal mortality are dystocia, starvation and misadventure. Observational studies have shown that loss of contact between the hind and calf, calf beating by hinds and entanglement of calves in fences are consequences of calving environments with high stocking densities, that lack vegetative or topographical cover, allow disturbance by humans, or provide unfamiliar social or environmental conditions. Weaning is a second critical production phase when management affects productivity. Early post-weaning growth rates in calves weaned before the rut are not influenced readily by feed quality. Reducing weaning stress using management tools such as confining the calves indoors for a few days, or adding some unrelated hinds to the weaned group can improve weight gains at this time. Another option is to delay weaning until the calves are older. Mating time is a third critical period during which management needs to take behavioural needs into account. Appropriate stag-hind ratios and management at mating that increase the chances of conception have been identified. Suitable social conditions at mating differ between yearling and adult hinds. Fence line pacing is frequently observed at the above three critical times and can occur at other times of the year in response to unfavourable conditions. Pacing consumes energy and contributes to erosion and fence maintenance requirements. Attention to the behavioural needs of deer can help improve performance through appropriate management systems.
\end{abstract}

Keywords: behaviour, calving, fence pacing, management, mating, weaning

\section{Introduction}

Management practices influence deer behaviour. Deer are naturally wide-ranging grazer/browsers, with hinds living in family groups and stags associating with other stags for most of the year (Darling 1937; Clutton-Brock et al. 1982). Confinement behind fences, forced cohabitation with specific individuals, weaning, handling and yard confinement are all situations that farmed deer would avoid if given the choice. This review describes how management practices at calving, weaning and mating can create more or less suitable environments for farmed red deer, with direct effects on productivity.

\section{Calving}

Calving environments on deer farms can be less than ideal. Recent estimates of average mortality rates of intensively farmed deer calves during the perinatal period were $10 \%$ for adult hinds and $12 \%$ for yearlings (Asher 2000). Post-mortem studies identified common causes of perinatal mortality as dystocia, starvation and misadventure (Asher \& Adam 1985; Gill 1985; Audige 1995). Events leading to such problems as observed by Cowie et al. (1985) were calves beaten or accidentally trampled by alien hinds, following alien hinds, "stolen" by other periparturient hinds, lost due to disturbance during birth, observed pacing along fences in apparent search of cover, and entangled in or trapped on the wrong side of fences.

Problems at calving are also apparent in fence pacing behaviour seen in hinds. This behaviour can comprise a considerable amount of the hinds' activities, especially during the day prior to birth. In various studies, individual hinds were observed pacing on the day prior to birth in $28 \%, 44 \%$, and $40 \%$ of observations respecti vely (Pollard et al. 1998; Wass et al. in prep.; Deighton unpubl.). Pre-parturient pacing was shown to increase relative to walking, increased during human presence, and was directed disproportionately at certain fences (Pollard et al. 1998). It was also more prevalent in a small paddock close to human observers than in a larger more remote paddock (Deighton unpubl.). Thus pacing hinds may be experiencing stress, which may contribute to dystocia and impair mothering ability (Pollard \& Drewry 2002). Pacing may lead to encroachment on the birth sites of other hinds, leading to some of the problems outlined by Cowie et al. (1985).

The environmental needs of deer, to allow natural behaviour at calving to be expressed, are likely to include space and isolation, and low or scrubby cover for calving and calf hiding. This is because wild deer seek isolated, often higher altitude sites for calving, sometimes outside of their normal home range (Darling 1937; Clutton-Brock \& Guinness 1975). They calve within low vegetative cover such as reeds and scrub (Darling 1937; Clutton-Brock \& Guinness 1975). The young calf spends its first few days hiding in covered 
sites while its dam grazes far aw ay, often a kilometre or more, only returning to suckle 2-4 times per day (Darling 1937; Clutton-Brock \& Guinness 1975).

Some extensive properties, where large paddocks, low stocking densities and cover are normal features of the environment, have reported very low neonatal mortality rates of between 2 and $5 \%$ (T. Pearse pers. com.). A few intensive properties can also achieve very low calf mortality rates (Beatson et al. 2000). A difference of 5 to $8 \%$ calf mortality between different systems represents financial losses of $\$ 1000$ to $\$ 1600$ per 100 hinds, assuming a weaner (calf aged 3-4 months) value of $\$ 4 / \mathrm{kg}$ live weight, and assuming a live weight of $50 \mathrm{~kg}$.

Neonatal calf mortality and fence pacing by calving hinds are likely to be reduced by recognising and providing for the needs of the deer, which on the average farm may mean leaving gates open, leaving or creating rough cover, minimising stocking density, and keeping the deer in the least disturbed area of the farm.

\section{Weaning}

Weaning calves at the usual age of 3-4 months may create stress, evident in poor post-weaning calf growth rates, pacing along fences, calling between the hind and calf, and impaired immunocompetence (Griffin et al. 1988; Pollard et al. 1992; Pollard \& Littlejohn 2000; Beatson et al. 2000). Both social and nutritional stress is likely, as calves of this age are still dependent on their mothers' milk (Arman et al. 1974; Loudon et al. 1983; 1984). Pacing along fences can comprise a considerable amount of the calves' activities, for example in groups of 20 newly weaned deer, approximately half of each group was pacing at any one time on the day of weaning, and this gradually declined to about $7 \%$ of each group on the sixth day following weaning (Pollard \& Littlejohn 2000).

The importance of management factors in achieving good post-weaning growth rates was highlighted in a study comparing liveweight gain with pasture energy concentration. During the six weeks following weaning, pasture energy content was not strongly related to weight gain, in contrast to measurements made during late lactation or mid-winter (see Stevens et al. this volume, from Beatson et al. 2000).

Techniques to reduce weaning stress have been identified through experimentation and farmer innovation (summarised in Pollard 2001). These include confinement indoors for a few days, hand-feeding, weaning in good weather and providing shelter, minimising handling, using remote or adjacent paddocks for the separated hinds and calves, addition of unrelated adults to the calf group, gradual weaning by removing successive groups of hinds, maintaining social and environmental familiarity, and providing high quality, familiar feed (Moore et al. 1985; Griffin et al. 1988; Pollard et al. 1992; Milne 1993; Haigh et al. 1997; Church \& Hudson 1999; Beatson et al. 2000; Pollard \& Littlejohn 2000).

Most of the above techniques have been demonstrated to reduce pacing behaviour in calves, but studies of effects on growth rates have produced more variable results. Groups that were confined indoors immediately post-weaning for seven days, or had an unrelated adult hind added to the mob of weaned calves, each showed improvements in weight gain of approximately $70 \mathrm{~g} /$ day during the first 14 days post-weaning, compared with groups that were returned to pasture or left without a hind (Pollard et al. 1992). In a different study, calves housed indoors for six weeks following weaning gained more weight during that period ( $157 \mathrm{~g} /$ day) than calves grazed at pasture or housed for a shorter period (mean for other treatments $=58 \mathrm{~g} /$ day; Milne 1993). Leaving calves on their farm of origin, rather than transporting them a short distance to a new farm, resulted in a weight gain advantage of $43 \mathrm{~g} /$ day over the first 14 days postweaning (Pollard \& Littlejohn 2000). However weaning into adjacent paddocks (Haigh et al. 1997) or gradual removal of successive groups of hinds (Church \& Hudson 1999) did not affect post-weaning growth rates in wapiti.

An alternative means of achieving good autumn growth rates is to delay weaning for several months. Wild red deer do not normally wean offspring nutritionally until they are at least six or seven months old, and social contact is maintained well beyond this time (Darling 1937; Lowe 1966; Clutton-Brock et al. 1982). In a study of 10 commercial farms, calves weaned in February/March gained less weight during autumn than those weaned in May/June (142 vs. $210 \mathrm{~g} /$ day in Year 1 of the study, and 131 vs $166 \mathrm{~g} /$ day in Year 2). The weight advantage was still evident in September, despite a dip in post-weaning weight gain that occurred in the May/June weaned groups in Year 1 (Pollard et al. 2002). However, weaning late delayed hind conception date by 7-12 days and reduced hind condition score in winter by 0.3-0.5 units (Pollard et al. 2002).

The immune response to a vaccine given at weaning has been reported by Griffin et al. 1988. In a review of cases where the yersiniosis vaccine for deer had broken down, Brenton-Rule (2001) showed that $44 \%$ of cases had been first vaccinated at weaning (rather than before or after), $74 \%$ had been given multiple treatments at weaning and $35 \%$ had experienced a feed shortage or transition to another feed type. He concluded that weaning stress played a significant role in the response of the immune system to the vaccine. However further research found that weaning did not reduce the response to vaccination when the newly weaned calves were 
confined indoors on hard feed for three days before being vaccinated (Mackintosh pers. comm.).

The above demonstrates that good productivity over the weaning period cannot be guaranteed by simply providing good pasture. The producer needs to develop a management strategy that allows a smooth transition between the calves' pre-weaning and post-weaning nutritional environments, and minimises additional stress during the immediate post-weaning period.

\section{Mating}

In the wild, individual stags attempt to establish and defend a harem of hinds during the mating season. The dominant stags control the largest harems and perform the most mating, and the majority of stags do not mate (Darling 1937; Clutton-Brocket al. 1982).

In the farm situation, antagonistic behaviour and fence pacing are common behaviours in rutting stags (Moore et al. 1985). The importance of management factors in determining a successful outcome from this period is highlighted in the wide range of conception rates observed in individual herds (Beatson et al. 2000). On average, about $4 \%$ of adult hinds and $16 \%$ of yearling hinds fail to conceive (Asher \& Pearse 2002).

The number of stags and hinds in a group affect behaviour during the rut. If a few stags are added to hind groups during the rut, a dominant stag does most of the mating, and it has been recommended that one stag should be allocated to each hind group (Moore et al. 1985; Beatson et al. 2000). However if many stags are present the ability of one stag to retain harems is reduced (Bray \& Kelly 1979). Individual stags have been reported to be capable of serving up to 137 hinds (Beatsonet al. 2000), although observations of apparent sexual exhaustion (Moore et al. 1985) and the risk of poor conception rates from an inactive or infertile stag, have led to recommendations that approximately 50 hinds are allocated per stag (Moore et al. 1985, Asher \& Pearse 2002). "Exhausted" dominant stags still retained their harems, therefore it was necessary to remove the stag to allow another to take over mating (Moore et al. 1985). To minimise the risk of poor conce ption rates, it was recommended that stags were replaced after the first or second oestrus cycle (Moore et al. 1985, Beatson et al. 2000; Asher \& Pearse 2002). The minimum cost of a missed conception can be estimated to be the weaning value of that calf, with this value increasing if calves are retained and finished on the property.

Achieving good conception rates in 16 month old hinds is a current challenge to the deer industry (Asher $\&$ Pearse 2002). Preliminary observations indicated that young hinds should be mated in separate groups from adult hinds, as in mixed groups they tended to be chased by the adults to the periphery of the herd, and some stags appeared exhausted from mating by the time the young hinds exhibited oestrus (up to three weeks after the adults; Asher \& Pearse 2002). Some farmers felt that another problem was discrimination by stags against young hinds, or that the young hinds were intimidated by large stags (Asher \& Pearse 2002). Joining of young hinds in January/February with stags of the same age at stag: hind ratios of 1: 10 or 1:20 has been recommended (Audige et al. 1999a; Walker et al. 1999; Beatson et al. 2000; Asher \& Pearse 2002).

Paddock size affects behaviour during the rut. High levels of antagonism between stags were observed when paddocks were less than one hectare in size (Moore et al. 1985). The position of mating paddocks also affects behaviour. Antagonistic behaviour directed at the stag on the opposite side of the fence occurred frequently when mating stags were kept in adjacent paddocks, and it was suggested that to avoid this, paddocks should be separated or contiguous at just one corner (Moore et al. 1985). There is also evidence that to achieve good conception rates, mating mobs should be kept undisturbed in quiet areas of the farm, away from human activity (Audige et al. 1999b).

A relationship between antagonism and conception rate is unknown. No study to date has determined whether antagonistic activities displace mating behaviour in rutting stags.

In summary, observations to da te are that behaviour at mating time is optimised in specific environments. To achieve good conception rates;

- disturbance should be minimised

- adult hinds should be mated by one stag within groups of 50 hinds

- the stag should be replaced after one or two oestrus cycles

- young hinds are best joined with several yearling stags well before the mating season.

\section{Other times of the year}

Production losses associated with inappropriate environments are not confined to neonatal losses, poor growth rates and failure to conceive, but other effects have been less well documented. Fence pacing can occur at any time of the year in response to factors such as human disturbance, lack of sufficient feed, water or shelter, and disruption of social bonds (Moore et al. 1985). Pacing has tended to be associated with an increase in overall movement, and/or less resting activity (Haigh et al. 1997; Church \& Hudson 1999; Pollard et al. 1998; Pollard \& Littlejohn 1999; Pollard \& Littlejohn 2000). An additional undesirable effect of fence pacing is the creation of bare ground and compacted soil contributing to soil erosion (Pollard \& Drewry 2002), and an increased need for maintenance of fences. 
Fence pacing has a variable cost associated with it. This depends on the size of the animal, the topography of the environment and the speed of pacing. The cost of walking and trotting is calculated in Table 1 and expressed as the extra energy intake required per day. The fence pacing activity of a weaned calf of $50 \mathrm{~kg}$ may average $25 \%$ of its time during the first 6 days after weaning (Pollard \& Littlejohn 2000) or 4 to 6 hours per day. Using the data in Table 1, and assuming that fence pacing activity uses energy over and above normal acti vity, it is estimated that the calf will use an extra 4 to $10 \mathrm{MJME}$ per day when fence pacing, depending on the topography and the speed of travel. This translates into a growth rate potential of between 75 and $190 \mathrm{~g} / \mathrm{d}$ (53 MJME/kg liveweight gain, Stevens et al. 2003) for the 6 days. When translated into a 14 day post-weaning period this equates to live-weight gain that may be between 30 and $80 \mathrm{~g} / \mathrm{d}$ lower in unsettled calves compared with settled calves that are not pacing. These differences in live-weight gain are similar to those found in the literature and reported earlier in this paper (43 to $99 \mathrm{~g} / \mathrm{d}$ ).

The energy expended by a $110 \mathrm{~kg}$ hind spending a total of one hour a day pacing instead of resting, may vary between 2 and 4.5 MJME. When calving in a disturbed environment with pacing accounting for $40 \%$ of the day's activities this translates into a significant energy expenditure of between 19 and $43 \mathrm{MJME} / \mathrm{d}$. This

Table 1 Dietary energy requirement (MJ ME/h) when deer are fence pacing.

(These estimates are based on net energy required for the horizontal component of walking $=2.6 \mathrm{~kJ} / \mathrm{km} / \mathrm{kg} \mathrm{BW}$ and the vertical component of walking $=28.0 \mathrm{~kJ} / \mathrm{km} / \mathrm{kg} \mathrm{BW}$ (ARC 1980) and the conversion of metabolisable energy to net energy of 0.7 , with deer in undulating situations having a vertical movement of $25 \mathrm{~m} / \mathrm{h}$ and in steep situations having a vertical movement of 50 $\mathrm{m} / \mathrm{h}$, walking at $5 \mathrm{~km} / \mathrm{h}$ or trotting at $10 \mathrm{~km} / \mathrm{h}$ ).

Dietary energy requirement (MJ ME/h) when walking

\begin{tabular}{lccc} 
Liveweight $(\mathrm{kg})$ & Flat & Undulating & Steep \\
\hline 50 & 0.9 & 1.0 & 1.0 \\
70 & 1.3 & 1.4 & 1.4 \\
90 & 1.7 & 1.8 & 1.9 \\
110 & 2.0 & 2.2 & 2.3 \\
130 & 2.4 & 2.5 & 2.7 \\
150 & 2.8 & 2.9 & 3.1 \\
\hline
\end{tabular}

Dietary energy requirement (MJ ME/h) when trotting

Liveweight $(\mathrm{kg}) \quad$ Flat Undulating Steep

\begin{tabular}{llll}
\hline 50 & 1.9 & 2.0 & 2.1 \\
70 & 2.6 & 2.7 & 2.9 \\
90 & 3.3 & 3.5 & 3.7 \\
110 & 4.1 & 4.3 & 4.5 \\
130 & 4.8 & 5.1 & 5.3 \\
150 & 5.6 & 5.9 & 6.2 \\
\hline
\end{tabular}

occurs at a time when feed intake is naturally low (Mulley 2003) and so may translate into a body weight loss of 1 to $2 \mathrm{~kg}$.

Social environments can also affect grazing behaviour and growth. In a comparison of high (150 hinds/ha) and lower (37 hinds/ha) density treatments, disruption of grazing patterns and lower average growth rates were seen in the higher density treatment (Blanc \& Theriez 1998).

\section{Conclusions}

- Calving, weaning and mating are critical periods when productivity can be directly affected by management choices concerning the social and physical environments of deer.

- Ensuring that the behavioural requirements of deer are met can improve productivity.

- At each of these critical periods and at other times when conditions are unfavourable, deer have a propensity to pace along fences, which is another source of production loss through increased energy expenditure and erosion.

- Efforts to create more suitable environments may reduce the propensity to pace and enhance overall performance.

\section{REFERENCES}

ARC 1980. The nutrient requirements of ruminant livestock. Commonwealth Agricultural Bureaux, Farnham Royal.

Arman, P.; Kay, R.N.B.; Goodall, E.D.; Sharman, G.A.M. 1974. The composition and yield of milk from captive red deer (Cervus elaphus L.). Journal of Reproduction and Fentility 37: 67-84.

Asher, G.W. 2000. Improving the reproductive performance of the farmed red deer hind. Proceedings of the New Zealand Institute of Primary Industry Management Conference 2000: 126-138.

Asher, G.W.; Adam, L.J. 1985. Reproduction in farmed red and fallow deer in northern New Zealand. In: Fennessy, P.F., Drew, K.R. (Eds.), Biology of Deer Production, Royal Society Bulletin 22: 217-224.

Asher, G.W.; Pearse, A.J. 2002. Managing reproductive performance of farmed deer: The key to productivity. Proceedings of the Third World Deer Farming Congress, Austin, Texas, U.S.A.: 99-112.

Audige, L.M. 1995. Deer herd health and production profiling. PhD Thesis, Massey University.

Audige, L.M.; Wilson, P.R.; Morris, R.S. 1999a. Reproductive performance of farmed deer in New Zealand. II. Risk factors for adult hind conception. Preventative Veterinary Medicine 40:33-51.

Audige, L.J.M.; Wilson, P.R.; Morris, R.S. 1999 b. Reproductive performance of farmed red deer (Cervus 
elaphus) in New Zealand: III. Risk factors for yearling hind conception. Preventa tive Veterinary Medicine 40: 53-65.

Beatson, N.; Campbell, A.; Judson, G. 2000. Deer Industry Manual. Herald Communications, Timaru. 134 pp.

Blanc, F.; Theriez, M. 1998. Effects of stocking density on the behaviour and growth of farmed red deer hinds. Applied Animal Behaviour Science 56: 297-307.

Bray,A.R.; Kelly, R.W. 1979. Mating management and reproductive activity in intensively farmed red deer. Proceedings of the New Zealand Society of Animal Production 39: 94-99.

Brenton-Rule, T. 2001. Investigations of apparent vaccine breakdown. Proceedings of a Deer Course for Veterinarians 18: 19-21.

Church, J.S.; Hudson, R.J. 1999. Comparison of abrupt and interval weaning of farmed wapiti calves (Cervus elaphus). Small Ruminant Research 32: 119-124.

Clutton-Brock, T.H.; Guinness, F.E. 1975. Behaviour of red deer (Cervus elaphus L.) at calving time. Behaviour 55: 287-300.

Clutton-Brock, T.H.; Guinness, F.E.; Albon, S.D. 1982. Red Deer. Behaviour and Ecology of Two Sexes. University of Chicago Press, Chicago. 378 pp.

Cowie, G.M.; Moore, G.H.; Fisher, M.W.; Taylor, M.J. 1985. Calving behaviour of farmed red deer. Proceedings of the New Zealand VeterinaryAssociation Deer Branch Course No. 2: 143-154.

Darling, F.F. 1937. A Herd of Red Deer. Oxford University Press. 215 pp.

Deighton, M. Behaviour of red deer (Cervus elaphus) hinds calving in small or large paddocks. Unpublished Summer Research Report, AgResearch. 23 pp.

Gill, J.M. 1985. Perinatal calf loss in farmed deer at Invermay. Proceedings of the Deer Branch of the New Zealand Veterinary Association Conference 2: 186192.

Griffin, J.F.T.; Bisset, L.R.; Fisher, M.W. 1988. Influence of management stress on immunity in farmed deer. Proceedings of the Deer Branch of the New Zealand Veterinary Association Conference 5: 145-163.

Haigh, J.C.; Stookey, J.M.; Bowman, P.; Waltz, C. 1997. A comparison of weaning techniques in farmed wapiti (Cervus elaphus). Animal Welfare 1997: 255-264.

Loudon, A.S.I.; McNeilly, A.S.; Milne, J.A. 1983. Nutritional and lactational control of fertility in red deer. Nature 302: 145-147.

Loudon, A.S.I.; Darroch, A.D.; Milne, J.A. 1984. The lactation performance of red deer on hill and imporved species of pasture. Journal of Agricultural Science, Cambridge 102: 149-158.
Lowe, V.P.W. 1966. Observations on the dispersal of red deer on Rhum.In: Symposiums of the Zoological Society of London 18: 211-228.

Milne, J. 1993. Managing the weaned calf and its welfare implications - an EC project. Deer Farming 42: 5-6.

Moore, G.H.; Cowie, G.M.; Bray, A. R. 1985. Herd management of farmed red deer. In: Fennessy, P.F., Drew, K.R. (Eds.), Biology of Deer Production. The Royal Society of New Zealand, Bulletin 22: 343-353.

Mulley, R.C. 2003. The feed requirements of adult deer. The nutrition and management of deer on grazing systems. Grassland Research and Practice Series 9: 51-57.

Pollard, J.C. 2001. Getting the best from your weaners. New Zealand Deer Farming Annual 2001: 40-41.

Pollard, J.C.; Drewry, J. 2002. Calving environments for farmed red deer: a review of current knowledge and a pilot study on soil quality. Proceedings of the Deer Branch of the New Zealand Veterinary Association Conference 19: 97-104.

Pollard, J.C.; Littlejohn, R.P. 1999. Activities and social relationships of red deer at pasture. New Zealand Veterinary Joumal 47: 83-87.

Pollard, J.C.; Littlejohn, R.P. 2000. Effects of management at weaning on behaviour and weight gain of farmed red deer calves. Applied Animal Behaviour Science 67: 151-157.

Pollard, J.C.; Littlejohn, R.P.; Suttie, J.M. 1992. Behaviour and weight change of red deer calves during weaning. Applied Animal Behaviour Science 35: 23-33.

Pollard, J.C.; Grant, A.; Littlejohn, R.P. 1998. Fence line pacing in farmed red deer hinds at calving. Animal Welfare 7: 283-291.

Pollard, J.C.; Littlejohn, R.P.; Asher, G.W. 2002. Weaning date affects calf growth rates and hind conception dates in farmed red deer (Cervus elaphus). Animal Science 74: 111-116.

Stevens, D.R.; Webster, J.R.; Corson, I.D. 2003. Effects of seasonality and feed quality on the feed requirements and live weight gain of young deer - a review. The nutrition and management of deer on grazing systems. Grassland Research and Practice Series 9. 17-25.

Walker, I.; Fraser, R.; Mason, A.; Wilson, P. 1999. Richmond Wrightson deer performance project interim reproduction results. Proceedings of the Deer Branch New Zealand Veterinary Associa tion Conference 16: 85-90.

Wass, J.A.; Pollard, J.C.; Littlejohn, R.P. A comparison of the calving behaviour of adult and yearling red deer (Cervus elaphus) hinds. Applied Animal Behaviour Science(in preparation). 